\title{
Surgical resource utilization after initial treatment of infant hydrocephalus: comparing ETV, early experience of ETV with choroid plexus cauterization, and shunt insertion in the Hydrocephalus Clinical Research Network
}

\author{
Jonathan Pindrik, MD, ${ }^{1}$ Jay Riva-Cambrin, MD, MSc, ${ }^{2}$ Abhaya V. Kulkarni, MD, PhD, ${ }^{3}$ \\ Jessica S. Alvey, MSc, ${ }^{4}$ Ron W. Reeder, PhD, ${ }^{4}$ lan F. Pollack, MD, ${ }^{5}$ John C. Wellons III, MD, MSPH, ${ }^{6}$ \\ Eric M. Jackson, MD, ${ }^{7}$ Curtis J. Rozzelle, MD, ${ }^{8}$ William E. Whitehead, MD, MPH, ${ }^{9}$ \\ David D. Limbrick Jr., MD, PhD, ${ }^{10}$ Robert P. Naftel, MD, ${ }^{6}$ Chevis Shannon, MBA, MPH, DrPH, ${ }^{6}$ \\ Patrick J. McDonald, MD, MHSc, ${ }^{11}$ Mandeep S. Tamber, MD, PhD, ${ }^{11}$ Todd C. Hankinson, MD, ${ }^{12}$ \\ Jason S. Hauptman, MD, PhD, ${ }^{13}$ Tamara D. Simon, MD, MSPH, ${ }^{13}$ Mark D. Krieger, MD, ${ }^{14}$ \\ Richard Holubkov, PhD, ${ }^{15}$ and John R. W. Kestle, MD, ${ }^{4}$ for \\ the Hydrocephalus Clinical Research Network
}

'Division of Pediatric Neurosurgery, Department of Neurological Surgery, Nationwide Children's Hospital, The Ohio State University College of Medicine, Columbus, Ohio; 'Section of Pediatric Neurosurgery, Division of Neurosurgery, Alberta Children's Hospital, University of Calgary, Alberta, Canada; ${ }^{3}$ Division of Neurosurgery, Hospital for Sick Children, University of Toronto, Ontario, Canada; ${ }^{4}$ Department of Neurosurgery, University of Utah, Salt Lake City, Utah; ${ }^{5}$ Department of Neurosurgery, Children's Hospital of Pittsburgh, University of Pittsburgh School of Medicine, Pittsburgh, Pennsylvania; ${ }^{6}$ Division of Pediatric Neurosurgery, Department of Neurosurgery, Monroe Carell Jr. Children's Hospital at Vanderbilt, Vanderbilt University Medical Center, Nashville, Tennessee; 'Department of Neurosurgery, Johns Hopkins Children's Center, Johns Hopkins University School of Medicine, Baltimore, Maryland; ' Division of Pediatric Neurosurgery, Department of Neurosurgery, Children's of Alabama, University of Alabama School of Medicine, Birmingham, Alabama; ' $D$ Department of Neurosurgery, Texas Children's Hospital, Baylor College of Medicine, Houston, Texas; ${ }^{10}$ Division of Pediatric Neurosurgery, Departments of Neurological Surgery and Pediatrics, St. Louis Children's Hospital, Washington University School of Medicine in St. Louis, Missouri; ${ }^{11}$ Division of Neurosurgery, University of British Columbia, Vancouver, British Columbia, Canada; ${ }^{12}$ Departments of Neurosurgery and Pediatrics, Children's Hospital Colorado, University of Colorado School of Medicine, Aurora, Colorado; ${ }^{13}$ Division of Pediatric Neurosurgery, Department of Neurosurgery, Seattle Children's Hospital, University of Washington, Seattle, Washington; ${ }^{14}$ Department of Surgery, Children's Hospital of Los Angeles, California; and ${ }^{15} \mathrm{Hydrocephalus} \mathrm{Clinical} \mathrm{Research} \mathrm{Network} \mathrm{Data}$ Coordinating Center, Department of Pediatrics, University of Utah, Salt Lake City, Utah

OBJECTIVE Few studies have addressed surgical resource utilization-surgical revisions and associated hospital admission days-following shunt insertion or endoscopic third ventriculostomy (ETV) with or without choroid plexus cauterization (CPC) for CSF diversion in hydrocephalus. Study members of the Hydrocephalus Clinical Research Network (HCRN) investigated differences in surgical resource utilization between CSF diversion strategies in hydrocephalus in infants. METHODS Patients up to corrected age 24 months undergoing initial definitive treatment of hydrocephalus were reviewed from the prospectively maintained HCRN Core Data Project (Hydrocephalus Registry). Postoperative courses (at 1,3 , and 5 years) were studied for hydrocephalus-related surgeries (primary outcome) and hospital admission days related to surgical revision (secondary outcome). Data were summarized using descriptive statistics and compared using negative binomial regression, controlling for age, hydrocephalus etiology, and HCRN center. The study population was organized into 3 groups (ETV alone, ETV with CPC, and CSF shunt insertion) during the 1st postoperative year and 2 groups (ETV alone and CSF shunt insertion) during subsequent years due to limited long-term follow-up data.

RESULTS Among 1090 patients, the majority underwent CSF shunt insertion (CSF shunt, 83.5\%; ETV with CPC, 10.0\%; and ETV alone, 6.5\%). Patients undergoing ETV with CPC had a higher mean number of revision surgeries $(1.2$

ABBREVIATIONS AS = aqueductal stenosis; $\mathrm{CPC}=$ choroid plexus cauterization; $\mathrm{ETV}=$ endoscopic third ventriculostomy; $\mathrm{HCRN}=$ Hydrocephalus Clinical Research Network; IIHS = International Infant Hydrocephalus Study; IVH = intraventricular hemorrhage.

SUBMITTED November 4, 2019. ACCEPTED April 6, 2020.

INCLUDE WHEN CITING Published online June 19, 2020; DOI: 10.3171/2020.4.PEDS19632. 
$\pm 1.6)$ than those undergoing ETV alone $(0.6 \pm 0.8)$ or CSF shunt insertion $(0.7 \pm 1.3)$ over the 1st year after surgery $(p=$ 0.005). At long-term follow-up, patients undergoing ETV alone experienced a nonsignificant lower mean number of revision surgeries $(0.7 \pm 0.9$ at 3 years and $0.8 \pm 1.3$ at 5 years) than those undergoing CSF shunt insertion ( $1.1 \pm 1.9$ at 3 years and $1.4 \pm 2.6$ at 5 years) and exhibited a lower mean number of hospital admission days related to revision surgery (3.8 \pm 10.3 vs $9.9 \pm 27.0, p=0.042$ ).

CONCLUSIONS Among initial treatment strategies for hydrocephalus, ETV with CPC yielded a higher surgical revision rate within 1 year after surgery. Patients undergoing ETV alone exhibited a nonsignificant lower mean number of surgical revisions than CSF shunt insertion at 3 and 5 years postoperatively. Additionally, the ETV-alone cohort demonstrated significantly fewer hospital admission days related to surgical management of hydrocephalus within 3 years after surgery. These findings suggest a time-dependent benefit of ETV over CSF shunt insertion regarding surgical resource utilization.

https://thejns.org/doi/abs/10.3171/2020.4.PEDS19632

KEYWORDS endoscopic third ventriculostomy; choroid plexus cauterization; shunt; cerebrospinal fluid; resource utilization; Hydrocephalus Clinical Research Network; HCRN

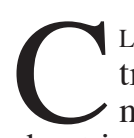

LINICAL controversy remains regarding the optimal treatment strategy for permanent CSF diversion in new-onset hydrocephalus. Prior studies evaluating shunt insertion, endoscopic third ventriculostomy (ETV), and/or ETV with choroid plexus cauterization (CPC) have focused on standard outcome measures. Perioperative mortality rates have remained low among patients undergoing ETV with CPC (0\%-2\%) or CSF shunt insertion $(0 \%) .^{1-6}$ While both types of procedures are associated with low rates of neurological morbidity, neuroendoscopic approaches have exhibited lower rates of CSF infection $(1 \%-6 \%)$ than has CSF shunt surgery $(6 \%-15 \%),{ }^{1,2,4,7-14}$ Rates of shunt infection per procedure vary between $4 \%$ and $17 \%$ based on multiple studies, ${ }^{3,7-16}$ with greater risk ratios demonstrated following shunt revision (1 revision, HR $3.0-3.9 ; \geq 2$ revisions, HR $6.5-13.0) .^{13,14}$ Measures developed and adopted by the Hydrocephalus Clinical Research Network (HCRN) have resulted in an 18\% risk reduction of time to first shunt failure ${ }^{17}$ and a $3 \%$ decline $(8.5 \%-5.7 \%)$ in shunt infection rates within HCRN centers. ${ }^{9}$ Despite these efforts and the use of antibiotic-impregnated catheters, rates of shunt failure at various centers may reach as high as $40 \%-50 \%$ within the first $1-2$ years following insertion or revision. ${ }^{11,18,19}$

Reported rates of treatment success following CSF diversion vary based on sample population characteristics and follow-up duration. Shunt success rates reached $61 \%$ and $47 \%$ at 1 and 2 years, respectively, in a randomized trial comparing shunt valve types..$^{16}$ In contrast, the International Infant Hydrocephalus Study (IIHS) demonstrated higher shunt success rates of $88 \%, 83 \%$, and $79 \%$ at 6 , 12 , and 36 months, respectively, for infants undergoing first-time treatment of obstructive hydrocephalus due to aqueductal stenosis (AS). ${ }^{3}$ However, postoperative success rates may decrease to around $40 \%$ at 4 years after CSF shunt insertion for other etiologies of hydrocephalus. ${ }^{6}$ Long-term shunt failure rates may reach as high as 63\%$80 \%$ per patient over $10-12$ years. ${ }^{7,20}$

In select patient populations, ETV may offer higher success rates. Warf reported success rates around $80 \%$ for ETV alone in infants older than 1 year treated in sub-Saharan Africa. ${ }^{4,5}$ Infants younger than 1 year exhibited lower success rates (40\%-59\%, depending on the etiology of hydrocephalus) after ETV. ${ }^{5}$ Other studies have demonstrated ETV success rates of $64 \%-66 \%$ at the 6- to 36-month follow-up and 52\% at the 5-year follow-up among infants with AS and pediatric patients with various etiologies of hydrocephalus., ${ }^{1,3}$ The addition of CPC to ETV (first reported as a combined procedure in 2005) has augmented clinical outcomes in hydrocephalic infants younger than 1 year., ${ }^{2,-6}$ Warf and Stone reported success rates of 59\%-66\% for ETV with CPC compared with $47 \%$ for ETV alone in prospective studies from Uganda and a North American center., ${ }^{41}$ Specific subpopulations, including premature infants with posthemorrhagic hydrocephalus, have exhibited lower success rates (37\%) following ETV with CPC. ${ }^{7}$ Meta-analyzed pooled success rates following ETV with CPC vary (mean 63\%, range 54\%-72\%), with dichotomized results between sub-Saharan African (71\% success rate) and North American (49\% success rate) populations. ${ }^{6}$

Few (if any) studies have examined potential differences in surgical resource utilization - the number of surgical revisions and hospital admission days related to surgical management of hydrocephalus-between initial treatment strategies. Conducted by members of the HCRN, this study investigated differences in surgical resource utilization between CSF shunt insertion and ETV with or without CPC as initial treatment strategies for permanent CSF diversion in infant hydrocephalus.

\section{Methods}

This study analyzed prospectively collected data within the HCRN's Core Data Project (Hydrocephalus Registry). Pediatric patients with a corrected age of 24 months or younger, undergoing initial definitive treatment of hydrocephalus at any institution within the HCRN before January 1, 2013 (for CSF shunt insertion and ETV alone), or before September 30, 2015 (for ETV with CPC), were studied for demographic information (corrected age at the time of treatment, sex, and ethnicity), etiology of hydrocephalus, initial surgical treatment of hydrocephalus, and clinical outcomes following surgery at 1,3 , and 5 years. Based on similar dates selected for a separate research study design (yielding similar subject cohorts), the earlier date of subject inclusion for CSF shunt and ETV-alone cohorts would allow for a more prolonged (5-year) outcome assessment, while the later date for the ETV with CPC cohort would allow for greater subject recruitment (while 
sacrificing longer-term follow-up) given the more recent widespread adoption of this surgical approach. Follow-up information for at least 12 months after surgery represented an inclusion criterion. The 16 etiologies of hydrocephalus in the patient population were collapsed into 4 categories (intraventricular hemorrhage [IVH] secondary to prematurity, myelomeningocele, AS, and other) for analysis. Study patients were divided into 3 cohorts based on initial treatment strategy: CSF shunt insertion, ETV alone, or ETV with CPC. The type of initial CSF diversion strategy for each study subject was selected by the treating surgeon based on clinical history, radiographic findings, training patterns, and practice preferences. Surgical treatments were performed with standard operative techniques as described previously, including the use of rigid or flexible endoscopy.

Primary and secondary outcome measures included the number (and type) of hydrocephalus-related surgeries after the initial treatment strategy (indicating failure of the treatment strategy) and the number of hospital admission days related to surgical management of hydrocephalus after the index procedure (including subsequent admissions), respectively. Based on data collected within the HCRN Core Data Project (Hydrocephalus Registry), only admission days involving immediate or eventual surgical revision (during the same admission) were counted, excluding observational admissions without surgery. Hospital admission days not involving surgical management of hydrocephalus (e.g., evaluation of shunt malfunction without progression to surgical intervention, management of urinary tract infections, evaluation of respiratory ailments or viral infections) were not included. Determinations of admission, length of stay, and discharge were based on clinical indices in a provider-dependent fashion (per standard of care). All outcomes were attributed to the initial treatment strategy utilized (CSF shunt insertion, ETV alone, or ETV with CPC) regardless of subsequent crossovers. Additionally, a discrete variable was recorded for each study subject reflecting the complexity of shunt system present at each follow-up time point $(1,3$, and 5 years): no shunt system, simple shunt system (1 proximal catheter and 1 distal catheter), and complex shunt system (more than 1 proximal catheter).

During the 1st year after surgery, primary and secondary outcome measures were compared among the 3 cohorts: ETV alone, ETV with CPC, and CSF shunt insertion. In subsequent years, the limited availability of long-term follow-up data for patients undergoing ETV with CPC restricted analysis to a comparison between ETV alone and CSF shunt insertion. Despite this limitation in prolonged follow-up for the ETV with CPC cohort, we elected to proceed with comparison of all 3 cohorts through the 1-year follow-up and comparison of 2 of the 3 treatment groups at the 3- and 5-year follow-ups. This initiative would allow evaluation of short-term outcomes and serve as a precursor to a subsequent study investigating long-term outcomes for all 3 treatment groups.

\section{Statistical Analysis}

Data elements were summarized using descriptive statistics and compared using regression models. More specif- ically, continuous variables were summarized using mean and SD, while categorical variables were summarized using frequencies and proportions. Negative binomial regression was used to assess the relationship between initial CSF diversion type and number of revisions. This method of analysis was used (as opposed to ANOVA) due to the discrete nature of the primary and secondary outcomes. Preliminary analysis of surgical outcomes stratified by HCRN site revealed statistically significant differences between sites regarding primary and secondary outcomes at all follow-up time points. Therefore, regression models controlled for HCRN center, corrected age (continuous), and collapsed hydrocephalus etiology (discrete). This type of analysis would help control for potential confounding factors in treatment outcome, including HCRN site and the application of ETV with CPC to infants with young age and IVH secondary to prematurity (typically shown to have lower success rates). In contrast, investigation of potential interactions between HCRN site or age and treatment type revealed no significant interaction terms for both outcome measures. Therefore, interactions between HCRN site or age and treatment type were not included in the statistical models. Covariates for regression were selected a priori. The number of hospitalization days related to surgical revision (according to initial CSF diversion strategy) was analyzed in analogous fashion.

\section{Results}

A total of 1090 study patients were included (shunt, 83.5\%; ETV with CPC, 10.0\%; and ETV alone, 6.5\%) with varying ages at treatment $(<1$ month, $53.0 \%$; 1 to $<$ 6 months, $25.1 \%$; 6 to $<12$ months, $12.2 \%$; and 12 to $\leq 24$ months, $9.6 \%$ ) and etiologies of hydrocephalus, including post-IVH secondary to prematurity $(26.0 \%)$, myelomeningocele (23.1\%), AS (11.9\%), and congenital communicating (8.2\%) (Fig. 1 and Table 1). Patients younger than 6 months and 12 months accounted for $78.2 \%$ and $90 \%$ of the study population, respectively. Data analysis after the 1st year of follow-up yielded comparisons among the 3 cohorts: ETV alone, ETV with CPC, and CSF shunt insertion (Table 2). However, at the time of last data analysis (2018), follow-up for patients within the ETV with CPC cohort did not extend to 3 and 5 years. Consequently, data analysis during these longer follow-up periods compared ETV alone and CSF shunt insertion (Table 3).

\section{Comparison of 1-Year Outcomes Between ETV Alone, ETV With CPC, and CSF Shunt Insertion}

Over the 1st year after surgery, patients undergoing ETV with CPC for initial treatment of hydrocephalus exhibited a higher mean number of hydrocephalus-related revision surgeries $(1.2 \pm 1.6)$ than those undergoing ETV alone $(0.6 \pm 0.8)$ or CSF shunt insertion $(0.7 \pm 1.3)(\mathrm{p}=$ 0.005 ) (Table 2). The mean number of hospital admission days related to surgical management of hydrocephalus (ETV alone, 4.2 \pm 13.2 ; ETV with CPC, $10.2 \pm 26.6$; and CSF shunt, 8.2 \pm 25.4 ) did not differ significantly between the 3 cohorts 1 year after surgery $(\mathrm{p}=0.96)$ (Table 2$)$.

The types of surgical revisions varied depending on the index treatment strategy for hydrocephalus. First-time CSF 

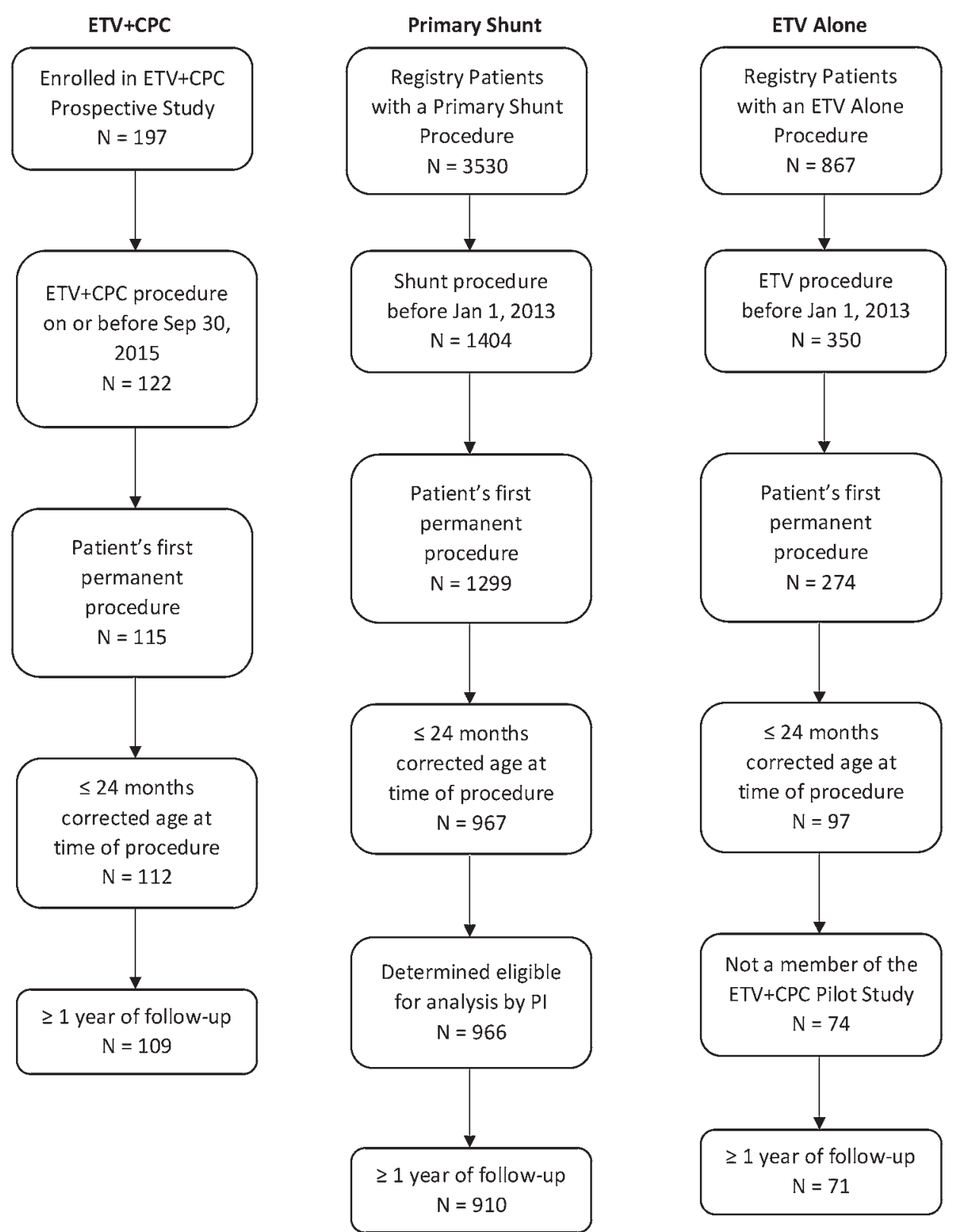

FIG. 1. Resource utilization CONSORT diagram. This figure demonstrates the distribution of the study sample population into 3 treatment-based cohorts utilizing a priori study inclusion and exclusion criteria. PI = primary investigator.

shunt insertion accounted for nearly $50 \%$ and more than $70 \%$ of total surgical revisions within 1 year after ETV with CPC and ETV alone, respectively (Table 4). Other types of surgical revisions within the endoscopic cohorts over the 1st year included ETV revision (ETV with CPC, $19.4 \%$ of surgical cases, and ETV alone, $7.3 \%$ ), CSF shunt revision excluding infection (ETV with $\mathrm{CPC}, 14.9 \%$, and ETV alone, 12.2\%), and CSF shunt removal/externalization or new insertion due to infection (ETV with CPC, 18.7\%, and ETV alone, 7.3\%) (Table 4). Within the CSF shunt cohort, revisions not related to infection accounted for almost $60 \%$ of the total surgical revisions within 1 year after initial treatment, while the proportion of surgical re- visions related to infection (CSF shunt removal/externalization and new CSF shunt insertion) accounted for 36\% of total surgical revisions (different from the overall infection rate) (Table 4).

\section{Comparison of Long-Term Outcomes Between ETV Alone and CSF Shunt Insertion}

While longer follow-up periods exhibited trends of fewer surgical revisions in the ETV-alone cohort, these differences did not meet statistical significance at 3 or 5 years between ETV alone $(0.7 \pm 0.9$ at 3 years and $0.8 \pm$ 1.3 at 5 years $)$ and CSF shunt insertion $(1.1 \pm 1.9$ at 3 years and $1.4 \pm 2.6$ at 5 years) $(\mathrm{p}=0.24$ at 3 years and $\mathrm{p}=0.17$ 
TABLE 1. Demographic characteristics and etiologies of hydrocephalus for the patients in this study

\begin{tabular}{|c|c|}
\hline & $\begin{array}{c}\text { No. of Patients } \\
(\%)\end{array}$ \\
\hline Total & 1090 \\
\hline \multicolumn{2}{|l|}{ Corrected age at 1st permanent CSF diversion, mos } \\
\hline$<1$ & $578(53.0)$ \\
\hline 1 to $<6$ & $274(25.1)$ \\
\hline 6 to $<12$ & $133(12.2)$ \\
\hline 12 to $\leq 24$ & $105(9.6)$ \\
\hline Male sex & $620(56.9)$ \\
\hline \multicolumn{2}{|l|}{ Ethnicity } \\
\hline Not Hispanic or Latino & $797(73.1)$ \\
\hline Hispanic or Latino & $140(12.8)$ \\
\hline Unknown or not reported & $153(14.0)$ \\
\hline \multicolumn{2}{|l|}{ Etiology } \\
\hline Postinfectious & $40(3.7)$ \\
\hline Post-IVH secondary to prematurity & $283(26.0)$ \\
\hline Myelomeningocele & $252(23.1)$ \\
\hline AS & $130(11.9)$ \\
\hline Spontaneous ICH/IVH/SAH & $37(3.4)$ \\
\hline Posterior fossa tumor & $21(1.9)$ \\
\hline Supratentorial tumor & $17(1.6)$ \\
\hline Midbrain tumor or other midbrain lesion & $4(0.4)$ \\
\hline Post-head injury & $26(2.4)$ \\
\hline Encephalocele & $19(1.7)$ \\
\hline Posterior fossa cyst, including Dandy-Walker & $55(5.0)$ \\
\hline Other intracranial cyst (e.g., arachnoid cyst) & $53(4.9)$ \\
\hline Congenital communicating hydrocephalus & $89(8.2)$ \\
\hline Other congenital (e.g., schizencephaly) & $29(2.7)$ \\
\hline Craniosynostosis & $10(0.9)$ \\
\hline Other etiology & $25(2.3)$ \\
\hline \multicolumn{2}{|l|}{ 1st permanent CSF diversion } \\
\hline ETV w/ CPC & $109(10.0)$ \\
\hline Shunt & $910(83.5)$ \\
\hline ETV alone & $71(6.5)$ \\
\hline
\end{tabular}

$\mathrm{ICH}=$ intracranial hemorrhage; $\mathrm{SAH}=$ subarachnoid hemorrhage .

at 5 years for ETV alone vs CSF shunt insertion) (Table 3). The mean number of hospital admission days related to surgical management of hydrocephalus (following index treatment) differed significantly between ETV alone (3.8 $\pm 10.3)$ and CSF shunt insertion $(9.9 \pm 27.0)$ at 3 years after surgery $(p=0.042)$. At 5 years after surgery, the mean number of hospital admission days demonstrated a similar trend favoring ETV alone $(4.4 \pm 11.7)$ compared with CSF shunt insertion $(11.8 \pm 32.5)$, without achieving statistical significance $(p=0.055)$ (Table 3$)$. The types and respective proportions (among total number of procedures) of surgical revisions at 3 and 5 years following initial CSF diversion strategy are reported in Tables 5 and 6.

In addition to primary and secondary outcome measures, the presence and complexity of ventricular shunt hardware in place at follow-up time points were investigated. Within
TABLE 2. Surgical resource utilization during the 1st year following index treatment for hydrocephalus

\begin{tabular}{lcccc}
\hline Outcome Measure & $\begin{array}{c}\text { ETV Alone } \\
(n=71)\end{array}$ & $\begin{array}{c}\text { ETV w/ CPC } \\
(n=109)\end{array}$ & $\begin{array}{c}\text { CSF Shunt } \\
(n=910)\end{array}$ & $\begin{array}{c}p \\
\text { Value }\end{array}$ \\
\hline Mean no. of revisions & $0.6 \pm 0.8$ & $1.2 \pm 1.6$ & $0.7 \pm 1.3$ & 0.005 \\
\hline $\begin{array}{l}\text { Mean no. of hospital } \\
\text { days }\end{array}$ & $4.2 \pm 13.2$ & $10.2 \pm 26.6$ & $8.2 \pm 25.4$ & 0.96 \\
\hline
\end{tabular}

Boldface type indicates statistical significance.

5 years following the initial surgery, $56.1 \%(32 / 57)$ of patients in the ETV-alone cohort and 1.7\% (13/754) of patients in the CSF shunt insertion cohort were shunt independent (no hardware in place). All remaining patients in the ETValone cohort $(25 / 57,43.9 \%)$ had a simple shunt system at 5-year follow-up. Over 95\% (719/754) of patients within the CSF shunt cohort had a simple shunt system, while nearly $3 \%(22 / 754)$ had a complex shunt system.

\section{Discussion}

Relatively few studies have offered direct comparisons between CSF diversion strategies. An HCRN multicenter retrospective study revealed higher success rates for CSF shunt insertion (72\% and 65\% at 6 and 12 months, respectively) than ETV with CPC (52\% at 6 and 12 months) for infants undergoing first-time treatment for hydrocephalus. $^{2}$ Contrasting these cumulative rates of success, Kulkarni et al. reported lower instantaneous failure risks for ETV beyond 3-6 months postoperatively when comparing cohorts from randomized CSF shunt trials and a multiinstitutional retrospective review of ETV..$^{16,18,22,23}$ Similar failure rates for CSF shunt insertion and ETV have been reported in several studies, including a quantitative meta-analysis by Rasul et al., ${ }^{24}$ a class II study by Tuli et al. (44\%-45\% failure rates among varying ages), ${ }^{20}$ and a class III study by Appelgren et al. (55\%-58\% failure rates with a mean follow-up period of 4.7 years). ${ }^{15}$ Based on systematic review of these and other articles, Limbrick et al. provided level II recommendations supporting either approach for treatment of pediatric hydrocephalus. ${ }^{25}$ Studies abroad, including a Nigerian prospective study by Uche et al., have demonstrated higher complication (9\%-15\%) and reoperation (20\%) rates after CSF shunt insertion than those after ETV (4\%-8\% and 4\%, respectively). ${ }^{26}$ In the first multiinstitutional prospective study comparing CSF shunt insertion and ETV, IIHS investigators demonstrated greater success rates with CSF shunt insertion (83\% at 12 months, $79 \%$ at 24 and 36 months) as opposed to ETV (66\% at 12 months, $64 \%$ at 24 and 36 months). ${ }^{3}$ These comparison studies help with the decision between treatment strategies for permanent CSF diversion but incorporate narrow sets of outcome measures.

The current study population includes infants requiring first-time permanent CSF diversion for definitive treatment of hydrocephalus, with the highest representation (78.2\%) among infants younger than 6 months. Incorporating a large sample population $(n=1090)$ and broad range of etiologies (e.g., posthemorrhagic hydrocephalus, myelomeningocele, AS, communicating congenital hydrocephalus), 
TABLE 3. Surgical resource utilization at 3 and 5 years following index treatment for hydrocephalus

\begin{tabular}{ccccc}
\hline Time From Index Surgery (yrs) & Outcome Measure & ETV Alone $(n=69)$ & CSF Shunt $(n=891)$ & $p$ Value \\
\hline \multirow{2}{*}{3} & Mean no. of revisions & $0.7 \pm 0.9$ & $1.1 \pm 1.9$ & 0.24 \\
\cline { 2 - 5 } & Mean no. of hospital days & $3.8 \pm 10.3$ & $9.9 \pm 27.0$ & $\mathbf{0 . 0 4 2}$ \\
\hline \multirow{2}{*}{5} & Mean no. of revisions & $0.8 \pm 1.3$ & $1.4 \pm 2.6$ & 0.17 \\
\hline & Mean no. of hospital days & $4.4 \pm 11.7$ & $11.8 \pm 32.5$ & 0.055 \\
\hline
\end{tabular}

Boldface type indicates statistical significance.

this study provides generalizable results applicable to the infant hydrocephalic population. The overrepresentation of CSF shunting (83.5\%) in comparison with ETV alone and ETV with CPC for initial CSF diversion reflects the traditional treatment approach to infants with hydrocephalus prior to 2013-2015. Current trends may differ given the recent advent and increasing popularity of ETV with CPC, including extension to etiologies of hydrocephalus outside of AS. The present study provides findings similar to those of previous large studies comparing CSF shunt insertion to ETV or ETV with CPC but quantified from a different perspective of surgical resource utilization. These findings agree with previously published results and suggest a time-dependent benefit of ETV over CSF shunt insertion regarding surgical resource utilization.

Patients undergoing ETV with CPC for initial treatment of hydrocephalus exhibited a higher mean number of hydrocephalus-related revision surgeries $(1.2 \pm 1.6)$ than those undergoing ETV alone $(0.6 \pm 0.8)$ or CSF shunt insertion $(0.7 \pm 1.3)$ over the 1 st year after surgery $(p=0.005)$. The greater mean number of surgical revisions following ETV with CPC compared with ETV alone likely reflected preoperative selection bias between the 2 groups, previous broader applications of ETV with CPC within infantile hydrocephalus, and willingness to attempt ETV with CPC in those patients with a lower preoperative likelihood of success after neuroendoscopic surgery. ${ }^{4,23}$ Specifically, the incorporation of patients with IVH secondary to prematurity may have influenced study findings, given the low rates of success of ETV with CPC reported in this subpopulation. ${ }^{7}$ Indeed, specific subgroup analysis for patients with IVH secondary to prematurity undergoing ETV with CPC revealed a higher mean number of revisions within 1 year after surgery $(2.0 \pm 2.6)$. Current trends reflecting narrower indications of ETV with CPC, typically excluding infants with IVH related to prematurity, may impact the surgical revision rate demonstrated in this study. Furthermore, recent advances in neuroendoscopy, including greater usage of flexible endoscopes and commitment to achieving $>90 \%$ CPC, might contribute to higher success rates following ETV with CPC currently. ${ }^{2}$ For long-term follow-up, the ETV-alone group exhibited a nonsignificant lower mean number of surgical revisions at 3 years $(0.7 \pm$ $0.9)$ and 5 years $(0.8 \pm 1.3)$ compared with the CSF shunt cohort (1.1 \pm 1.9 at 3 years and $1.4 \pm 2.6$ at 5 years). These differences did not achieve statistical significance, likely due to relatively large standard deviations and small sample sizes for the ETV-alone group.

While the ETV-alone group demonstrated fewer mean hospital admission days (4.2 \pm 13.16 days) related to surgical management of hydrocephalus, the differences in this secondary outcome did not achieve statistical significance between the 3 cohorts over the 1st year after surgery (Table 2). However, during long-term follow-up, the ETValone group exhibited significantly fewer hospital admission days (3.8 \pm 10.3 days) than the CSF shunt group (9.9 \pm 27.0 days) over 3 years following surgery $(\mathrm{p}=0.042)$ (Table 3). Similarly, the ETV-alone cohort experienced fewer hospital admission days related to surgical management of hydrocephalus at 5 years postoperatively, although this difference did not meet statistical significance. For comparison, a German study evaluating hospital resource utilization within the spina bifida population reported an annual average of 14.8 hospital days per patient for hydrocephalus and non-hydrocephalus-related management. ${ }^{27}$

Differences between HCRN centers regarding surgical outcomes were acknowledged and controlled for by study team members through statistical methods. Analysis of

TABLE 4. Types and proportions (among total procedures) of surgical revisions following index treatment for hydrocephalus at 1 year

\begin{tabular}{|c|c|c|c|c|c|c|c|}
\hline \multirow[b]{2}{*}{$\begin{array}{c}\text { Index } \\
\text { Procedure }\end{array}$} & \multicolumn{7}{|c|}{ Revision Type (\%)* } \\
\hline & $\begin{array}{l}\text { 1st-Time CSF } \\
\text { Shunt Insertion }\end{array}$ & $\begin{array}{c}\text { 1st-Time } \\
\text { ETV }\end{array}$ & $\begin{array}{c}\text { CSF Shunt } \\
\text { Revision (excluding } \\
\text { infection) }\end{array}$ & $\begin{array}{c}\text { ETV } \\
\text { Revision }\end{array}$ & $\begin{array}{l}\text { CSF Shunt Removal } \\
\text { or Externalization } \\
\text { (due to infection) }\end{array}$ & $\begin{array}{l}\text { New CSF Shunt } \\
\text { Insertion (following } \\
\text { infection) }\end{array}$ & Other† \\
\hline ETV w/ CPC & $63 / 134(47.0)$ & & $20 / 134(14.9)$ & $26 / 134(19.4)$ & $13 / 134(9.7)$ & $12 / 134(9.0)$ & \\
\hline ETV alone & $30 / 41(73.2)$ & & $5 / 41(12.2)$ & $3 / 41(7.3)$ & $2 / 41(4.9)$ & $1 / 41(2.4)$ & \\
\hline CSF shunt & & $12 / 661(1.8)$ & $382 / 661(57.8)$ & & $115 / 661(17.4)$ & $125 / 661(18.9)$ & $27 / 661(4.1)$ \\
\hline
\end{tabular}

* The proportions reported are based on the total number of surgical procedures (not patients) per cohort.

† Other types of surgical revisions include CSF shunt removal (due to infection) without replacement, CSF shunt removal (not due to infection), and CSF shunt infection with nontraditional treatment approach. 
TABLE 5. Types and proportions (among total procedures) of surgical revisions following index treatment for hydrocephalus at 3 years

\begin{tabular}{|c|c|c|c|c|c|c|c|}
\hline \multirow[b]{2}{*}{$\begin{array}{c}\text { Index } \\
\text { Procedure }\end{array}$} & \multicolumn{7}{|c|}{ Revision Type (\%) } \\
\hline & $\begin{array}{l}\text { 1st-Time } \\
\text { CSF Shunt } \\
\text { Insertion }\end{array}$ & $\begin{array}{c}\text { 1st-Time } \\
\text { ETV }\end{array}$ & $\begin{array}{c}\text { CSF Shunt } \\
\text { Revision (excluding } \\
\text { infection) }\end{array}$ & $\begin{array}{c}\text { ETV } \\
\text { Revision }\end{array}$ & $\begin{array}{l}\text { CSF Shunt Removal } \\
\text { or Externalization } \\
\text { (due to infection) }\end{array}$ & $\begin{array}{l}\text { New CSF Shunt } \\
\text { Insertion (following } \\
\text { infection) }\end{array}$ & Other† \\
\hline ETV alone & $31 / 47(66.0)$ & & $6 / 47(12.8)$ & $6 / 47(12.8)$ & $2 / 47(4.3)$ & $2 / 47$ (4.3) & \\
\hline CSF shunt & & $20 / 1003(2.0)$ & $630 / 1003(62.8)$ & $2 / 1003(0.2)$ & $154 / 1003(15.4)$ & $161 / 1003(16.1)$ & $36 / 1003(3.6)$ \\
\hline
\end{tabular}

* The proportions reported are based on the total number of surgical procedures (not patients) per cohort.

† Other types of surgical revisions include CSF shunt removal (due to infection) without replacement, CSF shunt removal (not due to infection), and CSF shunt infection with nontraditional treatment approach.

the variation in surgical outcomes between HCRN centers revealed that HCRN site had a statistically significant impact on the number of surgical revisions and hospital admission days due to revision at 1-, 3-, and 5-year outcomes. Therefore, the study team elected to control for HCRN site in the negative binomial regression models. In contrast, further investigation of the potential interaction between HCRN site and specific treatment type demonstrated no significant interaction terms for outcomes at all time points studied. Therefore, the interaction between HCRN site and CSF diversion strategy was not included in the statistical model. Similarly, further analysis investigating any potential interaction between age and treatment type revealed no statistically significant interaction terms of outcomes at all follow-up time points. The impact of surgical experience with CSF diversion procedures on outcomes was not investigated in this study since there are no current direct or standardized measures of experience among surgeons. Stratifying the experience of neurosurgeons based on operative volume would have involved arbitrary designations or thresholds that might not adequately reflect comfort level with these procedures. The influence of formal training in ETV with CPC on outcomes has been studied previously by the HCRN, without a significant impact or relationship identified. ${ }^{28}$

The types of surgical revisions following index treatment strategy followed expected trends. First-time CSF shunt insertion following ETV failure and CSF shunt revision following shunt malfunction (excluding infection) accounted for similarly high proportions of surgical revisions over 3 and 5 years following initial surgery (Tables 5 and 6). The currently presented ETV success rate (encompassing multiple etiologies of hydrocephalus in infants with corrected age $\leq 24$ months) agrees with previously published results, with $56.1 \%$ of patients remaining shunt independent at the 5-year follow-up. Index treatment strategy did not influence the complexity of the shunt system in place during prolonged follow-up. All patients undergoing initial ETV and more than $95 \%$ of patients undergoing initial CSF shunt insertion had a simple shunt system at 5 years after surgery.

\section{Study Limitations}

While incorporating a large study population with a wide breadth of hydrocephalus etiologies, we acknowledge certain study limitations. The overrepresentation of CSF shunt insertion and the relatively small size of the ETValone cohort may have hindered equivalent comparisons and reduced power to assess potential differences in the mean number of surgical revisions between ETV alone and CSF shunt insertion at 3 and 5 years postoperatively. The lack of prolonged follow-up for patients undergoing ETV with CPC precluded data analysis at 3 and 5 years postoperatively, restricting analysis to the ETV-alone and CSF shunt cohorts. Furthermore, the time period during which ETV with CPC patients were selected may reflect an earlier willingness to broaden applications for this procedure despite presumed suboptimal success rates anticipated with ETV alone. Specifically, the performance of ETV with CPC in premature infants with IVH and posthemorrhagic hydrocephalus likely impacted results in this study given the higher mean number of surgical revisions found in specific subgroup analysis. This may account for the greater mean number of surgical revisions after ETV with CPC compared with ETV alone over the 1st year after surgery (Table 2). The initial CSF diversion strategy for each patient was selected by the treating surgeon based on clinical history, radiographic parameters, training patterns, and practice preferences. Therefore, the potential for selec-

TABLE 6. Types and proportions (among total procedures) of surgical revisions following index treatment for hydrocephalus at 5 years

\begin{tabular}{|c|c|c|c|c|c|c|c|}
\hline \multirow[b]{2}{*}{$\begin{array}{c}\text { Index } \\
\text { Procedure }\end{array}$} & \multicolumn{7}{|c|}{ Revision Type (\%) ${ }^{*}$} \\
\hline & $\begin{array}{l}\text { 1st-Time } \\
\text { CSF Shunt } \\
\text { Insertion }\end{array}$ & $\begin{array}{c}\text { 1st-Time } \\
\text { ETV }\end{array}$ & $\begin{array}{c}\text { CSF Shunt } \\
\text { Revision (excluding } \\
\text { infection) }\end{array}$ & $\begin{array}{c}\text { ETV } \\
\text { Revision }\end{array}$ & $\begin{array}{l}\text { CSF Shunt Removal } \\
\text { or Externalization } \\
\text { (due to infection) }\end{array}$ & $\begin{array}{l}\text { New CSF Shunt } \\
\text { Insertion (following } \\
\text { infection) }\end{array}$ & Other† \\
\hline ETV alone & $26 / 44(59.1 \%)$ & & $7 / 44(15.9)$ & $5 / 44(11.4)$ & $3 / 44(6.8)$ & $3 / 44(6.8)$ & \\
\hline CSF shunt & & 18/1091 (1.6) & $731 / 1091(67.0)$ & $2 / 1091(0.2)$ & $148 / 1091(13.6)$ & $155 / 1091(14.2)$ & $37 / 1091(3.4)$ \\
\hline
\end{tabular}

* The proportions reported are based on total number of surgical procedures (not patients) per cohort.

† Other types of surgical revisions include CSF shunt removal (due to infection) without replacement, CSF shunt removal (not due to infection), and CSF shunt infection with nontraditional treatment approach. 
tion bias regarding initial treatment decisions represents a study limitation. Stricter indications, narrower application to those patients with higher preoperative predicted rates of success, exclusion of infants with IVH secondary to prematurity, and improved surgical technique (flexible endoscope, $>90 \%$ CPC) in recent years may alter study results. Furthermore, longer duration of follow-up would add insight into surgical resource utilization over more years after initial treatment of hydrocephalus. Reexamination of the data in a future study incorporating 3- and 5-year outcomes for the ETV with CPC cohort also could allow for combined-group analysis of neuroendoscopic treatment of hydrocephalus (ETV alone and ETV with CPC) compared with CSF shunt insertion.

Certain data elements were not analyzed in this study due to logistical limitations and perceived deviations from study aims. Incorporation of observational admission days without surgery into a broader secondary outcome variable (hospital admission days related to the management of hydrocephalus) would provide a more accurate assessment of overall (medical and surgical) resource utilization in the hydrocephalic population. Unfortunately, the HCRN Core Data Project (Hydrocephalus Registry) does not record hospital admission days unrelated to surgery, and the logistical demands of acquiring this information for all study subjects precluded collection and analysis of these data. An additional limitation involves the unanticipated effect from unmeasured confounding factors that may have influenced the initial treatment choice (CSF shunt insertion vs ETV with or without $\mathrm{CPC}$ ) and subsequent resource utilization. However, the impact from unmeasured confounding factors, such as the complexity of hydrocephalus for each individual subject, represents a ubiquitous concern in observational research studies.

\section{Conclusions}

In agreement with prior studies comparing clinical outcomes after ETV, ETV with CPC, and CSF shunt insertion, this study reports a statistically significant higher mean number of surgical revisions after ETV with CPC than after CSF shunt insertion and ETV alone over the 1st year after surgical treatment of infant hydrocephalus. Earlier broad applications of ETV with CPC, including infants with IVH related to prematurity, may contribute to the higher surgical revision rate. However, patients undergoing ETV alone demonstrated fewer surgical revisions than those undergoing CSF shunt insertion over 3 and 5 years following initial treatment, although this difference failed to meet statistical significance. Additionally, the ETV-alone cohort demonstrated significantly fewer hospital admission days related to surgical management of hydrocephalus over 3 years following initial surgery. These findings support previously published results and may suggest a time-dependent benefit of ETV over CSF shunt insertion regarding surgical resource utilization.

\section{Appendix HCRN Members}

The HCRN currently consists of the following clinical centers and investigators: Primary Children's Hospital, University of Utah (J. Kestle); Children's Hospital of Alabama, University of Alabama at Birmingham (C. Rozzelle); Hospital for Sick Children, University of Toronto (J. Drake, A. Kulkarni); Texas Children's Hospital, Baylor College of Medicine (W. Whitehead); Seattle Children's Hospital, University of Washington (S. Browd, T. Simon, J. Hauptman); Children's Hospital of Pittsburgh, University of Pittsburgh (I. Pollack); St. Louis Children's Hospital, Washington University in St. Louis (D. Limbrick); Monroe Carell Jr. Children's Hospital at Vanderbilt, Vanderbilt University Medical Center (J. Wellons, R. Naftel, C. Shannon); British Columbia Children's Hospital, University of British Columbia (M. Tamber, P. McDonald); Alberta Children's Hospital, University of Calgary (J. Riva-Cambrin); The Johns Hopkins Hospital (E. Jackson); Children's Hospital of Los Angeles (M. Krieger); Children's Hospital Colorado (T. Hankinson); Nationwide Children's Hospital (J. Pindrik); and HCRN Data Coordinating Center, Department of Pediatrics, University of Utah (R. Holubkov).

\section{Acknowledgments}

We thank our colleagues for their past and ongoing support of HCRN: D. Brockmeyer, M. Walker, R. Bollo, S. Cheshier, J. Blount, J. Johnston, B. Rocque, L. Acakpo-Satchivi, W. J. Oakes, P. Dirks, J. T. Rutka, M. Taylor, D. Curry, G. Aldave, R. Dauser, A. Jea, S. Lam, H. Weiner, T. Luerssen, R. Ellenbogen, J. Ojemann, A. Lee, A. Avellino, S. Greene, E. Tyler-Kabara, T. Abel, T. S. Park, J. Strahle, S. McEvoy, M. Smyth, N. Tulipan, A. Singhal, P. Steinbok, D. Cochrane, W. Hader, C. Gallagher, M. Benour, E. Kiehna, J. G. McComb, P. Chiarelli, A. Robison, A. Alexander, M. Handler, B. O’Neill, C. Wilkinson, L. Governale, A. Drapeau, J. Leonard, E. Sribnick, A. Shaikhouni, E. Ahn, A. Cohen, M. Groves, S. Robinson, C. M. Bonfield.

In addition, our work would not be possible without the outstanding support of the dedicated personnel at each clinical site and the data coordinating center. Special thanks goes to: L. Holman, J. Clawson, P. Martello, N. Tattersall, T. Bach (Salt Lake City); A. Arynchyna, A. Bey (Birmingham); H. Ashrafpour, M. Lamberti-Pasculli, L. O'Connor (Toronto); E. Sanchez, E. Santisbon, S. Martinez, S. Ryan (Houston); A. Anderson, G. Bowen (Seattle); K. Diamond, A. Luther (Pittsburgh); A. Morgan, H. Botteron, D. Morales, M. Gabir, D. Berger, D. Mercer (St. Louis); A. Wiseman, J. Stoll, D. Dawson, S. Gannon (Nashville); A. Cheong, R. Hengel (British Columbia); R. Rashid, S. Ahmed (Calgary); M. Alrefaie, R. Daniel, A. Loudermilk (Baltimore); N. Rea, C. Cook (Los Angeles); S. Staulcup (Aurora); A. Sheline (Columbus); and N. Nunn, M. Langley, V. Wall, D. Austin, B. Conley, V. Freimann, L. Herrera, B. Miller (Utah Data Coordinating Center).

The HCRN has received funding, some contributing directly to the Core Data Project, from private philanthropy, the Hydrocephalus Association, the National Institutes of Health/National Institute of Neurological Disorders and Stroke (NIH/NINDS; grant nos. 1U01NS107486-01A1 and 1RC1NS068943-01), the Patient Centered Outcome Research Institute (PCORI; grant no. CER-1403-13857), and the Gerber Foundation (reference no. 16923638 ). None of the sponsors participated in the design or conduct of this study; collection, management, analysis, or interpretation of the data; or preparation, review, or approval of this manuscript. The study's contents are solely the responsibility of the authors and do not necessarily represent the official view of the sponsors.

\section{References}

1. Drake JM. Endoscopic third ventriculostomy in pediatric patients: the Canadian experience. Neurosurgery. 2007;60(5):881-886.

2. Kulkarni AV, Riva-Cambrin J, Browd SR, et al. Endoscopic third ventriculostomy and choroid plexus cauterization in infants with hydrocephalus: a retrospective Hydrocephalus 
Clinical Research Network study. J Neurosurg Pediatr. 2014;14(3):224-229.

3. Kulkarni AV, Sgouros S, Constantini S. International Infant Hydrocephalus Study: initial results of a prospective, multicenter comparison of endoscopic third ventriculostomy (ETV) and shunt for infant hydrocephalus. Childs Nerv Syst. 2016;32(6):1039-1048.

4. Warf BC. Comparison of endoscopic third ventriculostomy alone and combined with choroid plexus cauterization in infants younger than 1 year of age: a prospective study in 550 African children. J Neurosurg. 2005;103(6)(suppl):475-481.

5. Warf BC. Hydrocephalus in Uganda: the predominance of infectious origin and primary management with endoscopic third ventriculostomy. J Neurosurg. 2005;102(1)(suppl):1-15.

6. Weil AG, Westwick H, Wang S, et al. Efficacy and safety of endoscopic third ventriculostomy and choroid plexus cauterization for infantile hydrocephalus: a systematic review and meta-analysis. Childs Nerv Syst. 2016;32(11):2119-2131.

7. Chamiraju P, Bhatia S, Sandberg DI, Ragheb J. Endoscopic third ventriculostomy and choroid plexus cauterization in posthemorrhagic hydrocephalus of prematurity. J Neurosurg Pediatr. 2014;13(4):433-439.

8. Govender ST, Nathoo N, van Dellen JR. Evaluation of an antibiotic-impregnated shunt system for the treatment of hydrocephalus. J Neurosurg. 2003;99(5):831-839.

9. Kestle JR, Riva-Cambrin J, Wellons JC III, et al. A standardized protocol to reduce cerebrospinal fluid shunt infection: the Hydrocephalus Clinical Research Network Quality Improvement Initiative. J Neurosurg Pediatr. 2011;8(1):22-29.

10. Riva-Cambrin J, Kestle JR, Holubkov R, et al. Risk factors for shunt malfunction in pediatric hydrocephalus: a multicenter prospective cohort study. J Neurosurg Pediatr. 2016;17(4):382-390.

11. Sciubba DM, Noggle JC, Carson BS, Jallo GI. Antibioticimpregnated shunt catheters for the treatment of infantile hydrocephalus. Pediatr Neurosurg. 2008;44(2):91-96.

12. Sciubba DM, Stuart RM, McGirt MJ, et al. Effect of antibiotic-impregnated shunt catheters in decreasing the incidence of shunt infection in the treatment of hydrocephalus. J Neurosurg. 2005;103(2)(suppl):131-136.

13. Simon TD, Butler J, Whitlock KB, et al. Risk factors for first cerebrospinal fluid shunt infection: findings from a multicenter prospective cohort study. J Pediatr. 2014;164(6):14621468.e2

14. Simon TD, Whitlock KB, Riva-Cambrin J, et al. Revision surgeries are associated with significant increased risk of subsequent cerebrospinal fluid shunt infection. Pediatr Infect Dis J. 2012;31(6):551-556.

15. Appelgren T, Zetterstrand S, Elfversson J, Nilsson D. Longterm outcome after treatment of hydrocephalus in children. Pediatr Neurosurg. 2010;46(3):221-226.

16. Drake JM, Kestle JR, Milner R, et al. Randomized trial of cerebrospinal fluid shunt valve design in pediatric hydrocephalus. Neurosurgery. 1998;43(2):294-305.

17. Kulkarni AV, Riva-Cambrin J, Butler J, et al. Outcomes of CSF shunting in children: comparison of Hydrocephalus Clinical Research Network cohort with historical controls: clinical article. J Neurosurg Pediatr. 2013;12(4):334-338.

18. Kestle JR, Drake JM, Cochrane DD, et al. Lack of benefit of endoscopic ventriculoperitoneal shunt insertion: a multicenter randomized trial. J Neurosurg. 2003;98(2):284-290.

19. Robinson S. Neonatal posthemorrhagic hydrocephalus from prematurity: pathophysiology and current treatment concepts. J Neurosurg Pediatr. 2012;9(3):242-258.

20. Tuli S, Alshail E, Drake J. Third ventriculostomy versus cerebrospinal fluid shunt as a first procedure in pediatric hydrocephalus. Pediatr Neurosurg. 1999;30(1):11-15.

21. Stone SS, Warf BC. Combined endoscopic third ventriculostomy and choroid plexus cauterization as primary treatment for infant hydrocephalus: a prospective North American series. J Neurosurg Pediatr. 2014;14(5):439-446.

22. Kulkarni AV, Drake JM, Kestle JR, et al. Predicting who will benefit from endoscopic third ventriculostomy compared with shunt insertion in childhood hydrocephalus using the ETV Success Score. J Neurosurg Pediatr. 2010;6(4):310-315.

23. Kulkarni AV, Drake JM, Mallucci CL, et al. Endoscopic third ventriculostomy in the treatment of childhood hydrocephalus. J Pediatr. 2009;155(2):254-259.e1.

24. Rasul FT, Marcus HJ, Toma AK, et al. Is endoscopic third ventriculostomy superior to shunts in patients with noncommunicating hydrocephalus? A systematic review and meta-analysis of the evidence. Acta Neurochir (Wien). 2013;155(5):883-889.

25. Limbrick DD Jr, Baird LC, Klimo P Jr, et al. Pediatric hydrocephalus: systematic literature review and evidence-based guidelines. Part 4: Cerebrospinal fluid shunt or endoscopic third ventriculostomy for the treatment of hydrocephalus in children. J Neurosurg Pediatr. 2014;14(suppl 1):30-34.

26. Uche EO, Okorie C, Iloabachie I, et al. Endoscopic third ventriculostomy (ETV) and ventriculoperitoneal shunt (VPS) in non-communicating hydrocephalus $(\mathrm{NCH})$ : comparison of outcome profiles in Nigerian children. Childs Nerv Syst. 2018;34(9):1683-1689.

27. van Nooten FE, Winnette R, Stein R, et al. Resource utilization and productivity loss in persons with spina bifida - an observational study of patients in a tertiary urology clinic in Germany. Eur J Neurol. 2015;22(1):53-58.

28. Riva-Cambrin J, Kestle JRW, Rozzelle CJ, et al. Predictors of success for combined endoscopic third ventriculostomy and choroid plexus cauterization in a North American setting: a Hydrocephalus Clinical Research Network study. J Neurosurg Pediatr. 2019;24(2):105-215.

\section{Disclosures}

Dr. Limbrick: receives support of non-study-related research efforts from Microbot Medical, Inc. and Medtronic. Dr. Hauptman: consultant for Medtronic.

\section{Author Contributions}

Conception and design: Pindrik, Riva-Cambrin, Kulkarni, Kestle. Acquisition of data: Pindrik, Riva-Cambrin, Kulkarni, Pollack, Wellons, Jackson, Rozzelle, Whitehead, Limbrick, Naftel, Shannon, McDonald, Tamber, Hankinson, Hauptman, Simon, Krieger, Kestle. Analysis and interpretation of data: Pindrik, Riva-Cambrin, Kulkarni, Alvey, Reeder, Holubkov, Kestle. Drafting the article: Pindrik. Critically revising the article: Pindrik, Riva-Cambrin, Kulkarni, Alvey, Reeder, Pollack, Wellons, Jackson, Rozzelle, Whitehead, Limbrick, Naftel, Shannon, McDonald, Tamber, Hankinson, Hauptman, Simon, Kestle. Reviewed submitted version of manuscript: all authors. Approved the final version of the manuscript on behalf of all authors: Pindrik. Statistical analysis: Pindrik, Alvey, Reeder, Holubkov. Study supervision: Pindrik, Kestle.

\section{Supplemental Information \\ Previous Presentations}

Portions of this work were presented in oral format at the 46th Annual Meeting of the AANS/CNS Section on Pediatric Neurological Surgery, November 28-December 1, 2017, Houston, Texas.

\section{Correspondence}

Jonathan Pindrik: Nationwide Children's Hospital and The Ohio State University College of Medicine, Columbus, $\mathrm{OH}$. jonathan. pindrik@nationwidechildrens.org. 